$$
\text { CONF-9509100--23 }
$$

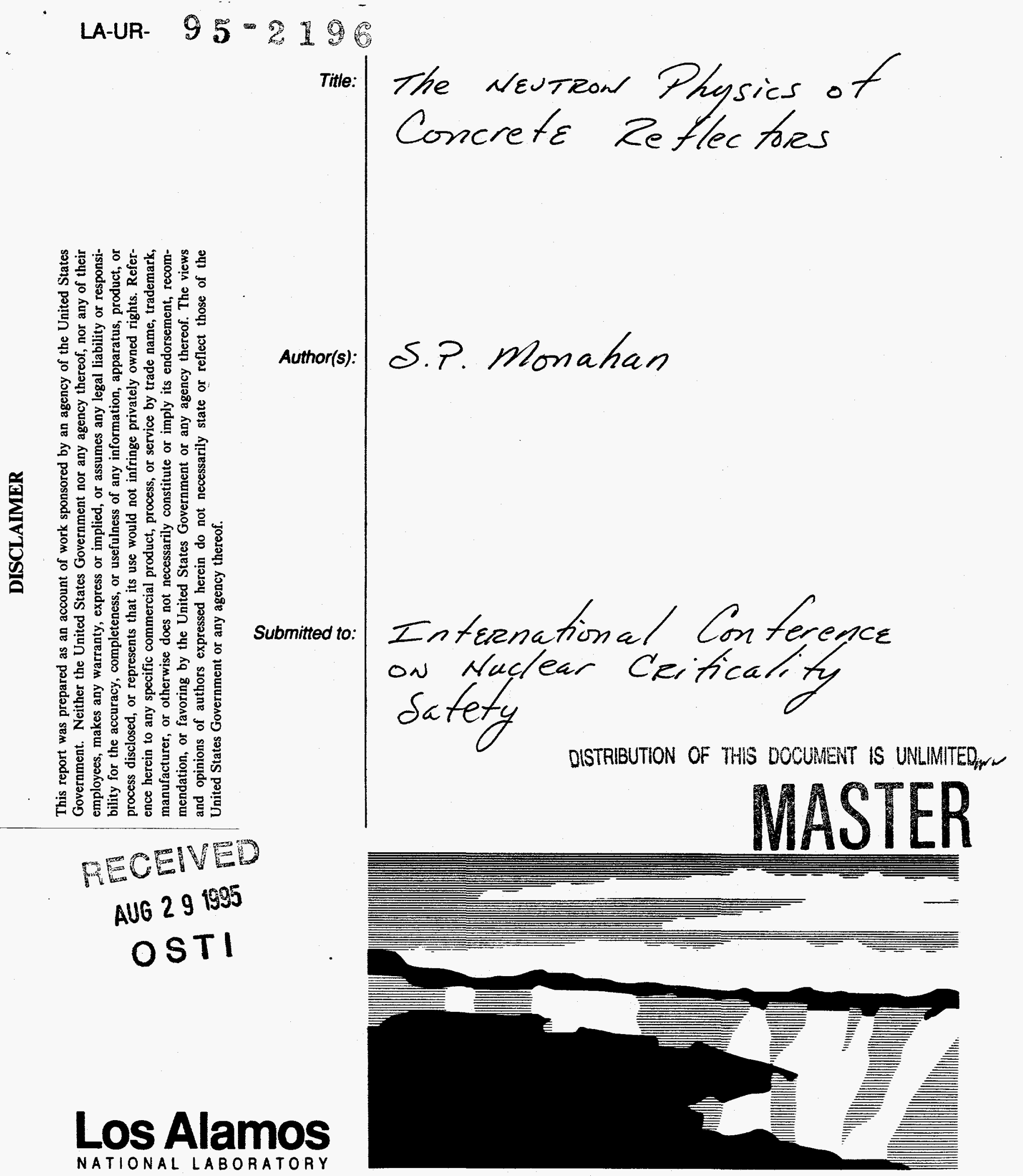

Los Alamos National Laboratory, an affirmative action/equal opportunity employer, is operated by the University of California for the U.S. Department of Energy under contract $W$-7405-ENG-36. By acceptance of this article, the publisher recognizes that the U.S. Government retains a nonexclusive, royalty-free license to publish or reproduce the published form of this contribution, or to allow others to do so, for U.S. Government purposes. The Los Alamos National Laboratory requests that the pubtisher identify this article as work performed under the auspices of the U.S. Department of Energy. 


\section{DISCLAIMER}

Portions of this document may be illegible in electronic image products. Images are produced from the best available original document. 


\title{
THE NEUTRON PHYSICS OF CONCRETE REFLECTORS
}

\author{
S. P. Monahan \\ Los Alamos National Laboratory \\ Nuclear Criticality Safety, ESH-6 \\ P.O. Box 1663, MS F691 \\ Los Alamos, New Mexico 87544 \\ 505665.2816 \\ 505665.4970 - FAX \\ wildcat@lanl.gov
}

\section{INTRODUCTION}

It has long been known that concrete reflection can be an important factor in determining the critical state of any fissile system, single unit or storage array. In fact, Section 5.4 of ANSI/ANS 8.7, "Guide For Nuclear Criticality Safety in the Storage of Fissile Materials"[1], states,

The mass limits in the tables are also applicable for concrete reflectors of thicknesses up to $127 \mathrm{~mm}$ (5 in.).... mass limits shall be reduced to $75 \%$ of stated values for a concrete reflector of $203 \mathrm{~mm}(8 \mathrm{in}$.) and to $60 \%$ for greater thicknesses.

Since there can be a large variation in the chemical makeup of concrete, the reduction factors are necessarily conservative, and may lead to a very uneconomical storage arrangement. In this case, relief is provided by the standard by allowing for "calculations specific to the system of interest."

However, for the purposes of computation the questions of the concrete makeup, and variations in that makeup, immediately arise. Differences in the composition of concrete and its effects on reactivity have been documented in the past [2,3]. As recently as 1990, the results of a study (based on Monte Carlo com- putations) concluded that the $\mathbf{k}_{\text {eff }}$ of a system, depending on the concrete mixture selected, could vary by as much as $24 \%$ for systems containing interstitial concrete, and as much as $12 \%$ for systems in which concrete was used as a reflector alone. The study goes on to conclude:

"Clearly, there is no substitute for calculating reality, i.e., one must know the constituents of the concrete of interest. In studies of exiting facilities, the analyst must obtain data on the existing concrete, preferably from physical and chemical analyses at various depths, or assume and verify that worst case selections have been made."

While it is agreed that the above statements are true for the most part, the bounds associated with the statements, "know the constituents", and "assume and verify worst case selections" are not clearly defined. As such this study was undertaken in an effort to clarify

1) the importance of the various concrete constituents and

2) to determine some general guidance as to the magnitude of the reactivity effects for the more likely fissile material storage conditions. 


\section{COMPARISON STUDY}

Using the ONEDANT [4] discrete ordinates code and the Hansen Roach 16 group cross section set [5], the neutron reflection and absorption behavior of eight different mixtures of concrete were compared. The concrete mixtures are listed in Table I in descending order of water content along with their reference sources.

Table I: Concrete Mixtures

\begin{tabular}{|l|c|c|}
\hline \multicolumn{1}{|c|}{ Mixture } & \% Water & Reference \\
\hline \hline Hanford & 10.99 & 6 \\
\hline Ordinary & 9.38 & 7 \\
\hline Regular & 8.94 & 8 \\
\hline Rocky Flats & 6.70 & 8 \\
\hline Oak Ridge & 5.53 & 8 \\
\hline NBS $^{\mathrm{a}}$ & 5.00 & 9 \\
\hline Los Alamos & 4.05 & 10 \\
\hline Magnuson & 2.97 & 8 \\
\hline
\end{tabular}

a. National Bureau of Standards

Table II shows the elemental components of each of these mixtures by weight percent. Examination of the table reveals that it is possible to categorize the mixtures into two basic sets, lime based, characterized by high calcium content, and silica based, characterized by high silicon content.

Figure 1 is a comparison of the fraction of neutrons absorbed and reflected as a function of reflector thickness. The results were obtained using a fixed neutron source incident on the left hand boundary of the media. The source was uniform, isotropic, and had the fission energy spectrum of U-235.

For concrete thicknesses below approxi- mately $25 \mathrm{~cm}(-10$ inches) it is difficult to discern any type of pattern in either the absorption or reflection curves. However, for thicknesses greater than $25 \mathrm{~cm}$, it is possible to make several conclusions,

1) the higher the water content, the greater the absorption fraction of the neutron population,

2) generally speaking the lower the water content, the more effective the mixture is as a reflector,

3) at $70 \mathrm{~cm}$ the neutron transmission for all of the mixtures is below $2 \%$ of the incident population,

4) $50 \mathrm{~cm}$ is essentially an infinite reflector thickness for each of the mixtures.

Despite the fact that these curves appear to form a distinctive pattern based on the water content alone, drawing conclusions about the general reactivity effects of the different mixtures is not possible with this information alone. Clearly, knowing the total fraction of neutrons reflected without any indication of potential differences in the spectral pattern, could lead to false conclusions.

In order to determine the reactivity differences, ONEDANT was again used. However, the curves of Figure 1 suggested that a different approach be taken in order to get at the desired result. Searches to determine the critical slab thicknesses for U(100) metal at 19.05 $\mathrm{g} / \mathrm{cc}$, and for a $40 \mathrm{~g} / \mathrm{U} \mathrm{U}(100)$ metal-water mixture were performed with the Hanford mixture (highest water content) as the reflector. Once these values had been determined as a function of reflector thickness, the Hanford concrete was simply replaced by the other seven mixtures (one at a time, of course) and a simple eigenvalue calculation was performed. The 
Table II: Concrete Mixtures by Weight Percent

\begin{tabular}{|c|c|c|c|c|c|c|c|c|}
\hline$\rho g / c c$ & $\begin{array}{l}\text { Han } \\
2.35\end{array}$ & $\begin{array}{l}\text { Ord } \\
2.37\end{array}$ & $\begin{array}{l}\text { Reg } \\
2.30\end{array}$ & $\begin{array}{c}\mathrm{RF} \\
2.321\end{array}$ & $\begin{array}{c}\text { OR } \\
2.2994\end{array}$ & $\begin{array}{l}\text { NBS } \\
2.35\end{array}$ & $\begin{array}{c}\text { LA } \\
2.25\end{array}$ & $\begin{array}{c}\text { Mag } \\
2.147\end{array}$ \\
\hline$\overline{\overline{\mathrm{H}}}$ & $\overline{1.23}$ & $\overline{1.05}$ & $\overline{\overline{1.0}}$ & $\overline{0.75}$ & 0.6187 & $\overline{0.56}$ & 0.453 & $\overline{0.3319}$ \\
\hline $\bar{C}$ & & 3.21 & & 5.52 & 17.52 & & & 10.53 \\
\hline$\overline{\mathbf{N}}$ & & & & 0.02 & & & & \\
\hline$\overline{0}$ & 51.3 & 46.54 & 53.2 & 48.49 & 41.02 & 49.56 & 51.26 & 49.94 \\
\hline $\mathrm{Na}$ & 0.2 & 0.49 & 2.9 & 0.63 & 0.0271 & 1.71 & 1.527 & 0.1411 \\
\hline$\overline{\mathbf{M g}}$ & 1.3 & 1.00 & & 1.25 & 3.261 & 0.24 & & 9.420 \\
\hline$\overline{\mathrm{Al}}$ & 6.4 & 1.39 & 3.4 & 2.17 & 1.083 & 4.56 & 3.555 & 0.7859 \\
\hline$\overline{\mathrm{Si}}$ & $\overline{25.6}$ & 11.88 & 33.7 & $\overline{15.5}$ & 3.448 & 31.35 & 36.036 & 4.210 \\
\hline$S$ & & & & 0.19 & & 0.12 & & 0.2483 \\
\hline$\overline{\mathrm{Cl}}$ & & & & & & & & 0.0523 \\
\hline$\overline{\mathbf{K}}$ & 1.2 & & & 1.37 & 0.1138 & 1.92 & & 0.9445 \\
\hline$\overline{\mathrm{Ca}}$ & 7.4 & 32.54 & 4.4 & 23.0 & 32.13 & 8.26 & 5.791 & 22.63 \\
\hline $\mathrm{Ti}$ & & & & 0.10 & & & & 0.1488 \\
\hline $\mathrm{Mn}$ & & & & & & & & 0.0512 \\
\hline $\mathrm{Fe}$ & 5.3 & 0.77 & 1.4 & 1.01 & 0.7784 & 1.22 & 1.378 & 0.5595 \\
\hline Total & 99.93 & 98.87 & 100.0 & 100.0 & 100.0 & 99.50 & 100.0 & 99.9935 \\
\hline
\end{tabular}

results of this comparison are shown graphically in Figures 2 and 3.

Confirmation of the previous [2] and dramatic differences in the calculated k-effectives is afforded by both of these figures, with the difference being as much as $8 \%$ (Los Alamos vs. Hanford) in the case the of a metal slab, and as much as 9\% (Magnuson vs. Hanford) in the case of the solution slab.

The shift in the identity of the most effective reflector is due to the differences in the energy spectra of the incident neutrons and in the two concrete mixtures. As the comparisons of Figures 4 and 5 show, there is no significant difference in the total absorption between these two mixtures in either case ${ }^{1}$. Consequently, the shift is likely due to differences in the reflected neutron spectra. In the case of the metal slab the Los Alamos mixture is a more effective moderator, leading eventually to a greater thermal neutron return than the Magnuson is able to produce. In the case of the solution slab since the energy spectrum of the neutrons entering the concrete is softer, the Magnuson mixture with its relatively high carbon content, is a more efficient thermal neutron reflector.

The second and more important item to note about these figures, is that eventually it is established that the drier mixtures are the more effective reflectors. While it is difficult and possibly dangerous to generalize below $\sim 35$ $\mathrm{cm}$, it is clear that above 35 centimeters, regardless of the other constituents within the

1. The small deviation in the thick reflector region of Figure 5, results in a difference in transmission, not reflection 

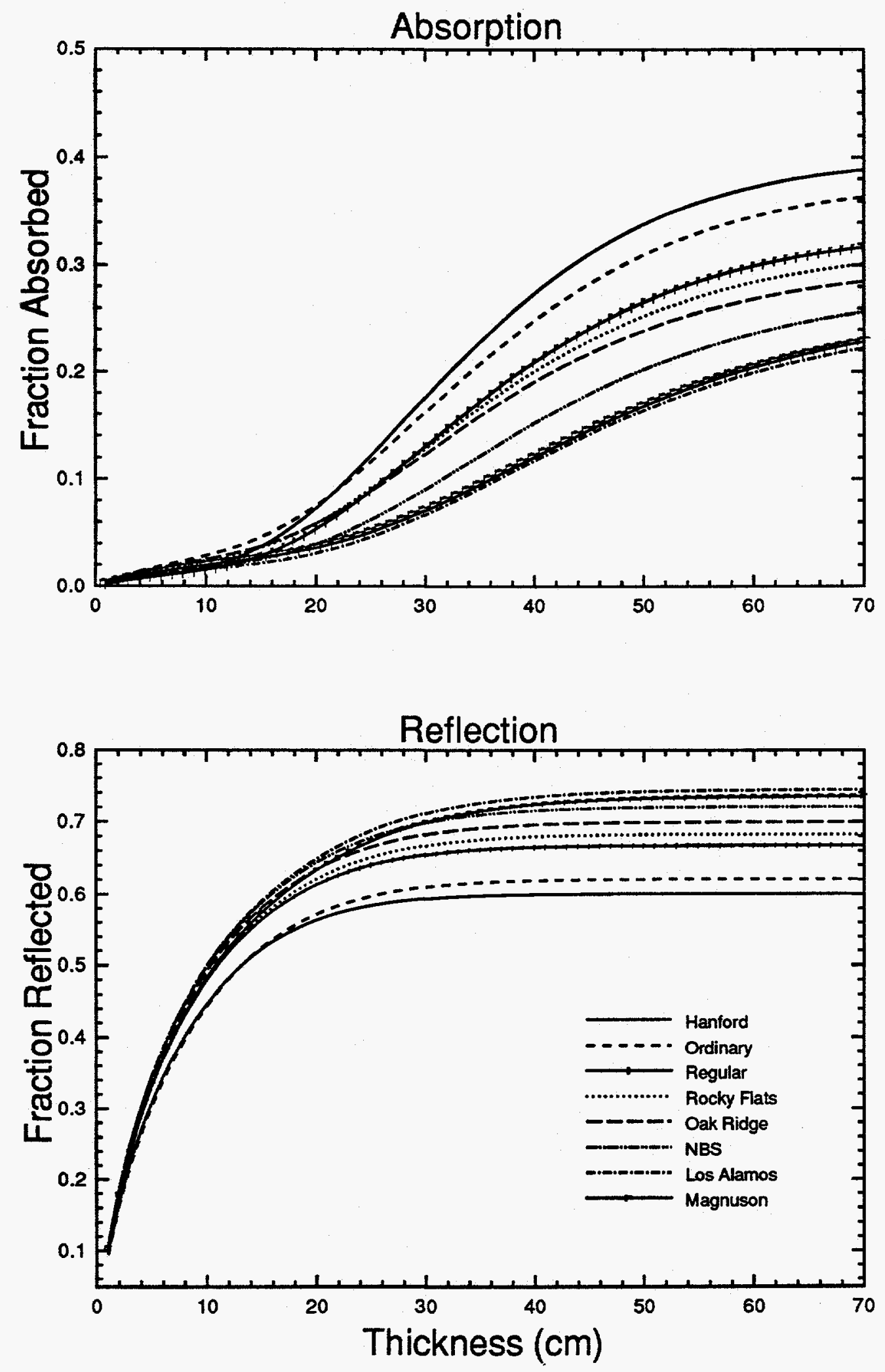

Figure 1. Absorption and reflection comparison 


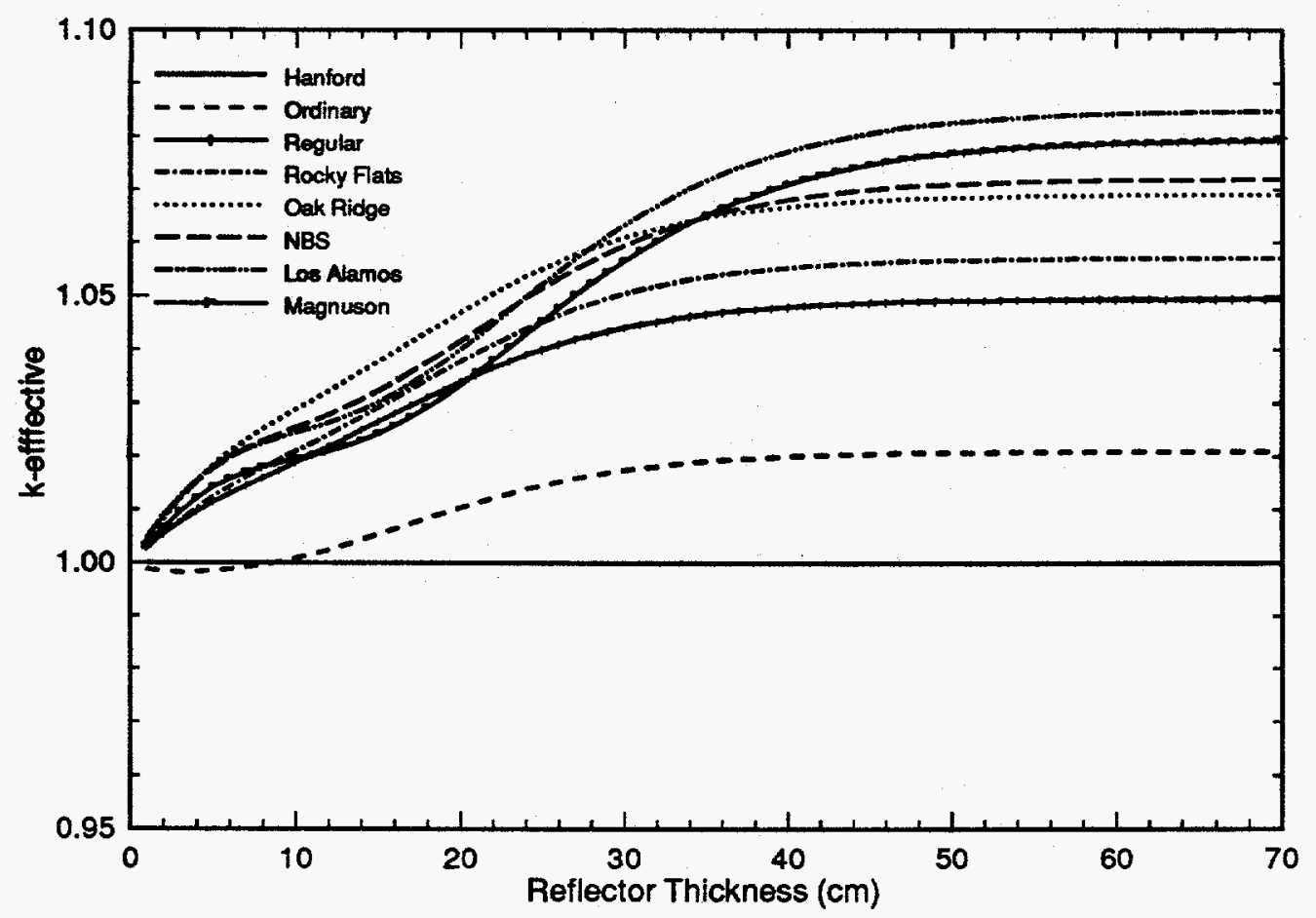

Figure 2. k-effective comparison for various concrete mixtures acting as a reflector for a $U(100)$ metal slab.

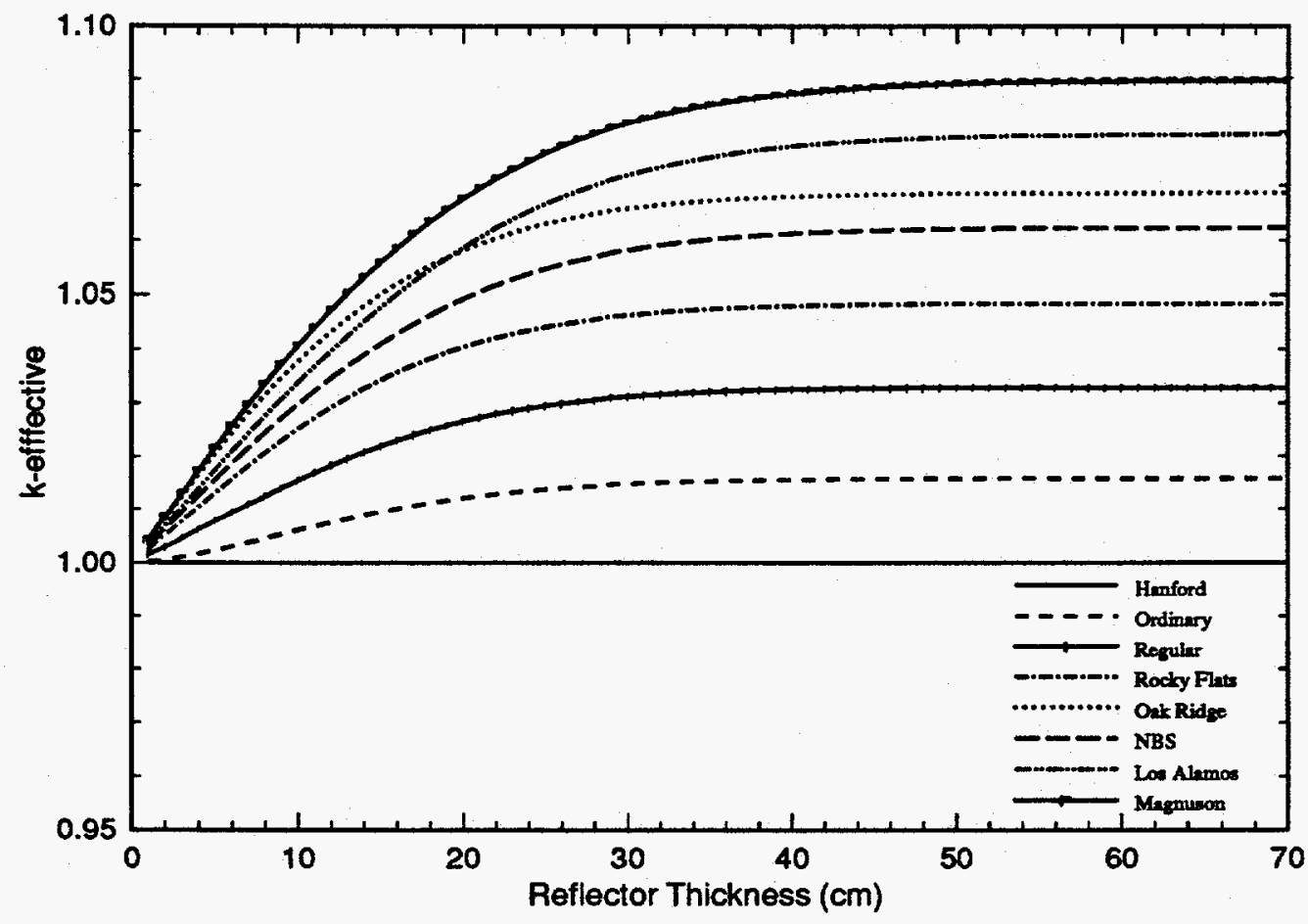

Figure 3. k-effective comparison for various concrete mixtures acting as a reflector for a $40 \mathrm{~g} / \mathrm{U} \mathrm{U}(100)$ metal-water solution slab 


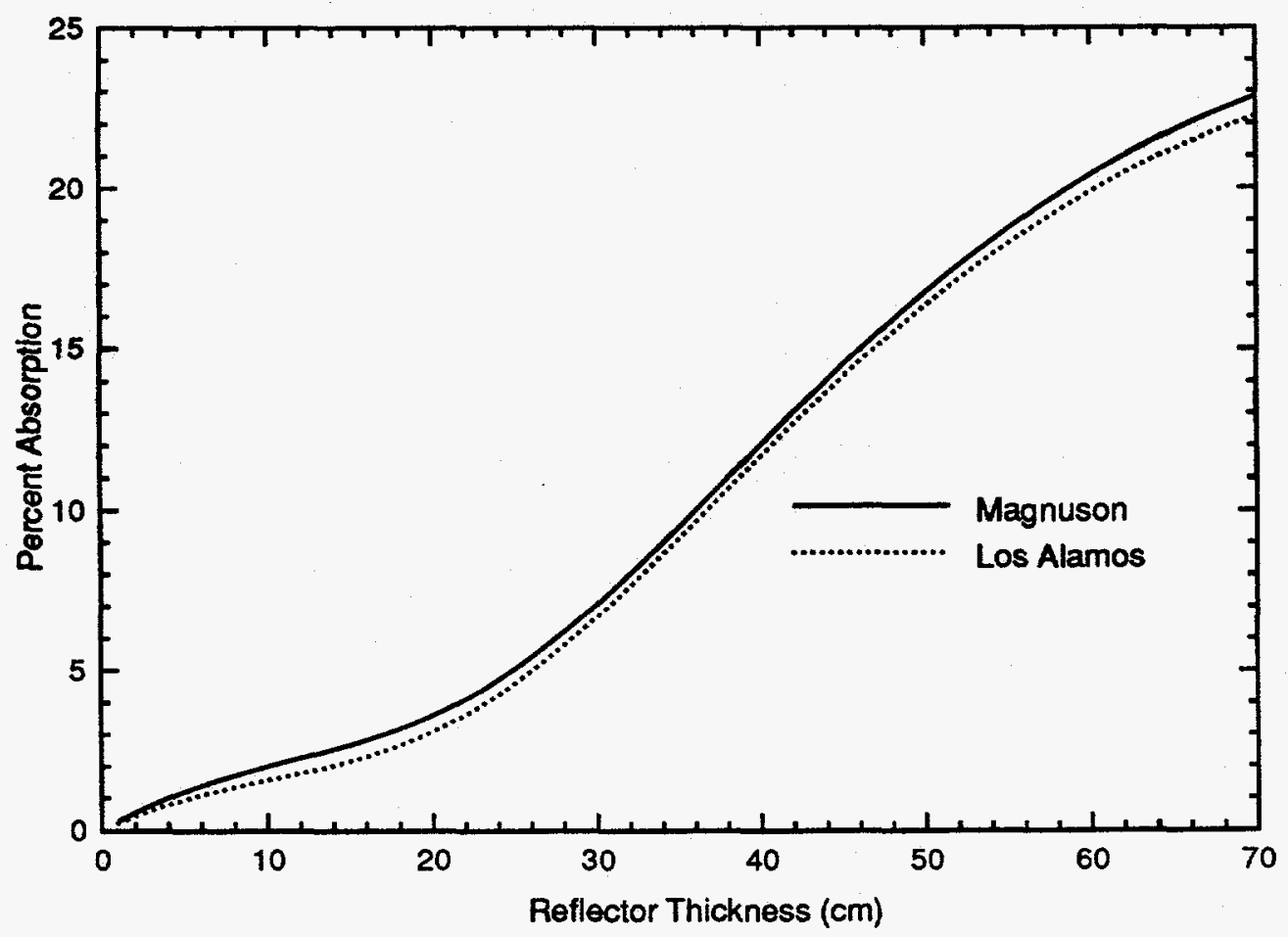

Figure 4. Absorption Comparison For Concrete Reflecting a U(100) Metal Slab

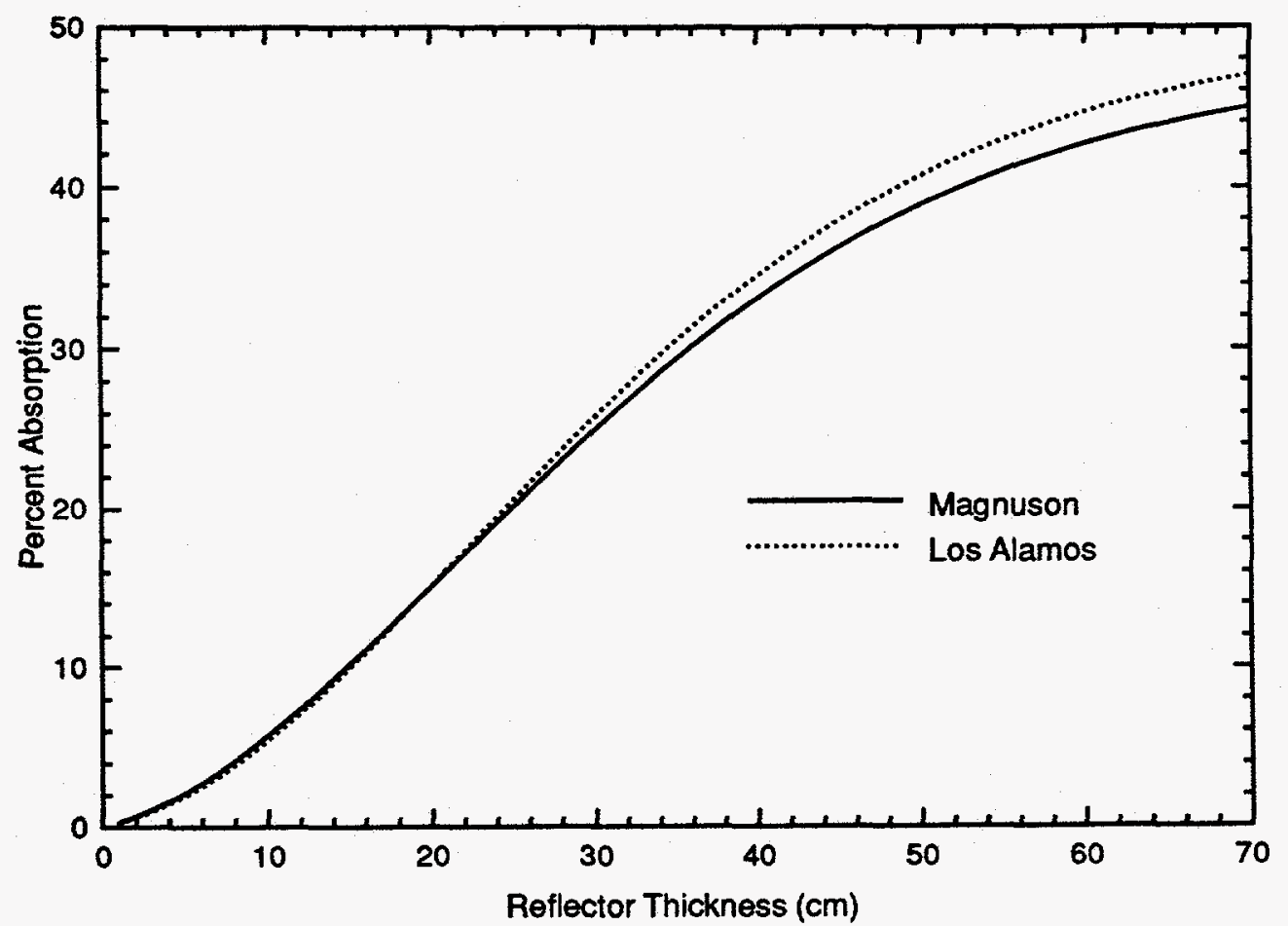

Figure 5. Absorption Comparison For Concrete Reflecting a $40 \mathrm{~g} / \mathrm{l}$ (100) Solution Slab 
concrete, that the water content controls the reactivity contribution of the mixture. After all, examination of Table II shows that the Los Alamos and Magnuson mixtures differ greatly in their compositional makeup, yet produce very similar calculational results. This is also born out by comparing the Los Alamos and Regular mixtures of Table $\mathrm{II}$. These two mixtures are essentially identical with the exception that the Regular mixture has slightly more than twice the water content, yet their reactivity contributions differ greatly. This is not to say that the other components are unimportant (since they provide a large degree of the absorption) but that their identities, i.e. whether it is a silica or lime based, with or without carbon, with or without any number of minor constituents, is unimportant for these thicknesses.

\section{APPLICATION OF RESULTS}

These results suggest that there may be conditions under which the requirement of identifying all of the material constituents of a concrete mixture may be relaxed. For vault storage situations in which the concrete appears as a reflector alone, conservative results can be assured by,

1) modeling the concrete at the thickness which maximizes the reactivity of the system, i.e., $\geq 50 \mathrm{~cm}$ for all mixtures (this, of course is not additionally conservative if the vault walls are $\geq 50 \mathrm{~cm}$ thick in reality),

2) using the most reactive concrete mixture, in this case Magnuson,

3) varying the water $(\mathrm{H})$ content to account for credible changes in the moisture content of the concrete with time.

While it may be argued that the Los Alamos mixture is slightly more reactive under some conditions (metal storage), the difference is inconsequential from a practical criticality safety perspective. Furthermore, item 3) from the list above would envelop any potential difference.

Finally, the question arises as to whether such an approach would result in any benefit or end up being just as conservative and uneconomical in terms of storage as direct application ANSI/ANS-8.7 [1] itself. Considering the magnitude of the differences as seen in Figures 2 and 3 of the previous section, this is not an unreasonable question. However, those results, because of the slab geometry of the fissile material, maximized the effects of and therefore the differences in the concrete mixtures. This geometric model is unrealistic for most vault storage conditions in which discrete items are stored with some type of spacing arrangement. Intuitively, the impact on reactivity of a concrete reflector, will be less for items that present smaller solid angles to the concrete face.

To illustrate consider the results shown in Table III that were generated by KENO V.a for a mock storage vault. The vault model consisted of $6.1 \times 3.7 \times 3.1$ meter volume in which $20 \mathrm{Kg} \mathrm{U}(100)$ metal spheres were placed in the geometric center of $70 \mathrm{~cm}$ cubic cells along all of the interior walls. The total vault load was then140 items. The vaults walls, floor, and ceiling were each $70 \mathrm{~cm}$ thick. For this portion of the study, only three mixtures, Hanford, Los Alamos and Magnuson were used. As the previous results suggested, the reactivity difference would be maximized by comparing the Hanford and Los Alamos mixtures. Magnuson was included to show that, indeed, the differences between the Los Alamos and Magnuson mixtures is inconsequential in practicality.

The results do show that reactivity difference in a realistic storage situation due to dif- 
ferences in the concrete mixtures is much smaller. These results also point out, for the same load per location, that the difference becomes larger as the solid angle of the objects being stored increases, but that this rise is also accompanied by a subsequent decrease in the $k$-effective of the system.

Clearly, under these circumstances, defaulting to the most reactive concrete mixture, would not lead to an inordinate reduction in the allowable mass storage limits.

Table III: Mock Vault Results: $20 \mathrm{Kg} /$ location

\begin{tabular}{|c|c|c|c|}
\hline & \multicolumn{3}{|c|}{ k-effective $^{\mathrm{a}}$} \\
\hline Density & Hanford & LA & Mag \\
\hline \hline Full $^{\mathrm{b}}$ & 0.89 & 0.92 & 0.92 \\
\hline $1 / 2$ & 0.70 & 0.75 & 0.74 \\
\hline $1 / 4$ & 0.63 & 0.70 & 0.68 \\
\hline
\end{tabular}

a. All standard deviations $\sim 0.003$

b. $19.05 \mathrm{~g} / \mathrm{cc}$

In conclusion, it should be strongly pointed out, that these results only apply to concrete as a reflector. These results are not applicable to situations in which concrete appears as an interstitial moderator, e.g., the use of concrete storage bins, or in the case of "vault pairs", as defined in ANSI/ANS-8.7 [1]. Obviously in such a situation, the reactivity affects of the different mixtures becomes much more complex.

\section{REFERENCES}

1. ANSI/ANS-8.7, "Guide For Nuclear Criticality Safety In The Storage of Fissile Material", American Nuclear Society, LaGrange Park, IL

2. G. R. Handley, R. C. Robinson, and J. C.
Cline, Transactions of the American Nuclear Society, 61, p 182 (1990).

3. R. D. Carter, "Concrete and Criticality", Report No. RHO-SA-30, June 1, 1978.

4. R. D. O'Dell, R. W. Brinkley Jr, D. R. Marr, and R. E. Alcouffe, "Revised User's Manual For ONEDANT: A Code Package for OneDimensional Diffusion Accelerated, NeutralParticle Transport", LA-9184-M, Los Alamos National Laboratory (1989).

5. G. E. Hansen, and W. H. Roach, "Six and Sixteen Group Cross Sections for Fast and Intermediate Critical Assemblies", LAMS2543, Los Alamos National Lab (1961).

6. R. C. Lloyd, C. R. Richey, E. D. Clayton, and D. R. Skeen, "Criticality Studies With Plutonium Solutions", Nuclear Science and Engineering, 25, pp. 165-173, (1966).

7. L. M. Petrie, and N. F. Cross, "KENO IV An Improved Monte Carlo Criticality Program", ORNL-4938, Oak Ridge National Lab, (1975).

8. "SCALE: A Modular Code System For Performing Standardized Computer Analysis For Licensing Evaluation", NUREG/CR-0200, Rev. 4, Oak Ridge National Lab (1993).

9. G. R. White, "X-Ray Attenuation Coeffcients From $10 \mathrm{Kev}$ to $100 \mathrm{Mev",} \mathrm{NBS} \mathrm{Report}$ No. 1003, (1952).

10. C. D. Harmon, II, R. D. Busch, J. F. Briesmeister, and R. A. Forster, "Criticality Calculations With MCNP: A Primer", LA-12827-M, Los Alamos National Lab (1994). 